\title{
Tumour of the glomus jugulare (non-chromaffin paraganglioma) of the ponto-cerebellar angle treated with $x$-irradiation
}

\author{
J. GRUSZKIEWICZ, ${ }^{1}$ M. GELDNER, AND A. BRYSZ \\ From the Neurosurgical Department, Tel-Hashomer Government Hospital, Israel
}

Tumours of the glomus jugulare expanding into the posterior fossa are of the utmost rarity. Most such tumours originate primarily in the middle ear and later tend to expand in the direction of the external auditory canal. They are, therefore, recognized as a rule at an otoscopic examination and, consequently, most references to this tumour are found in the oto-laryngological literature. According to Bickerstaff and Howell, only four out of 90 cases collected from the literature up to 1953 presented early neurological features. We have found only five welldocumented cases of tumour of the glomus jugulare expanding into the posterior fossa and originating in the paraganglionic structures of this region (Alexander, Beamer, and Williams, 1951; Albernaz and Bucy, 1953; Semmes, 1951; Meacham and Capps, 1960; Thoms, Shaw, and Trowbridge, 1960).

\section{CASE REPORT}

A woman aged 35 was admitted to the Tel-Hashomer Government Hospital on 4 April 1960. She complained of pain in her neck and in the back of her head of a year's duration, later accompanied by neck rigidity, left-sided headache, and a feeling of bruit in the left ear. Difficulties in swallowing and regurgitation and vomiting developed progressively. Because of severe dysphagia, she could be fed only through a gastric tube. Latterly, the patient complained of vertigo and unsteadiness and inability to stand and walk.

On admission, the patient looked very ill. She was fully conscious. Blood pressure was $120 / 70 \mathrm{~mm} . \mathrm{Hg}$ and the pulse rate $86 / \mathrm{min}$.

The chest was deformed by a thoracoplasty performed for tuberculosis in 1956. There was slight dullness to percussion. Coarse rales were present at the bases. The heart was normal. The abdomen was soft. The liver was palpable $1 \mathrm{~cm}$. below the right costal margin.

Neurological examination showed scanning speech, vertical nystagmus, and a positive Romberg sign, the patient tending to fall to the right and backwards.

Paresis of the fifth, seventh, eighth, ninth, tenth,

${ }^{1}$ Present address: Department of Neurosurgery, Rambam Government Hospital, Haifa, Israel. eleventh and twelfth cranial nerves was present on the left side, manifested by right-sided facial hypoaesthesia, lack of corneal, conjunctival, and masseter reflexes, $\vec{\circ}$ deafness, drooping of the left soft palate, and lack of gag reflex. There was also partial atrophy and weakness of the $\vec{\omega}$ left sternomastoid muscle and the left trapezius, and finally atrophy of the left side of the tongue.

Laboratory examination of blood and urine showed no: significant abnormality apart from anaemia $(\mathrm{Hb} 9.5 \mathrm{~g} . \%$, N haematocrit 29, and E.S.R. 120/140).

A radiograph of the skull showed destruction of these

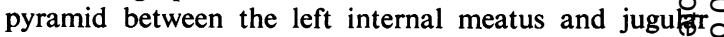
foramen (Fig. 1).

Otological examination showed normal tymparic membranes and total deafness on the left side. Vestibukgr TD tests showed no reaction to ice-water on the same side. 을

An E.E.G. showed a record of 10 to 11 waves/seg, occasionally decreasing to 5 to $6 / \mathrm{sec}$. The changes appeared on the left as well as on the right side, showi $\frac{\vec{g}}{\overrightarrow{0}} \overrightarrow{0}$ no tendency to lateralization.

On the basis of the clinical findings a pre-operative diagnosis of a left ponto-cerebellar tumour was made.

OPERATION On 3 May 1960 a left paramedial suboccipital craniectomy was performed. The dura mater was found to be under marked pressure. After making an $\bar{Q}$ occipital burr hole puncture of the lateral ventricle showed marked hydrocephalus. The bulging of the dura

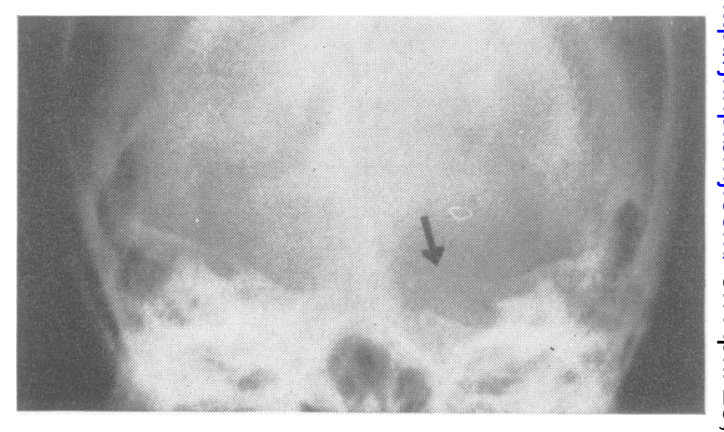

FIG. 1. Radiographs of the skull showing destruction of the left pyramid in the region of the jugular foramen. 


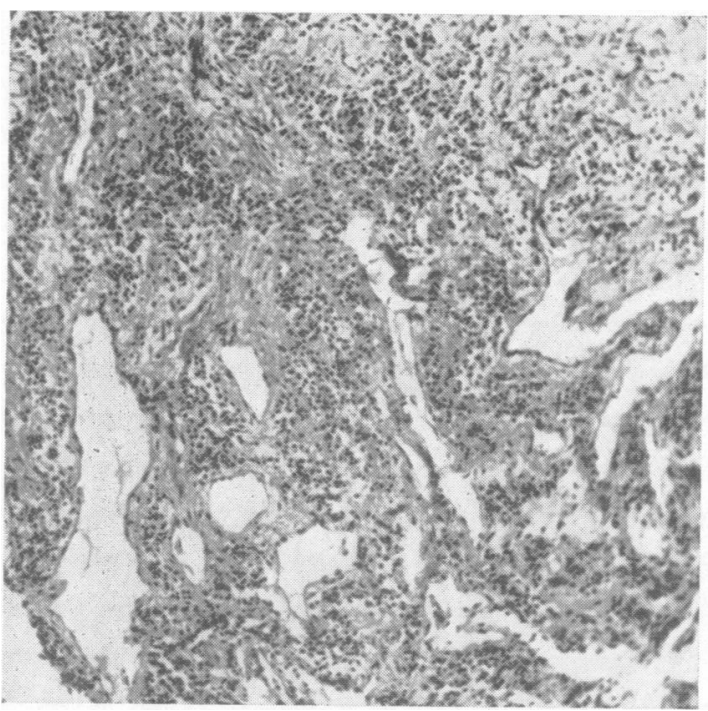

FIG. 2. An area of the tumour with a cavernomatous appearance because of dilated vascular channels and fibrosis. Haematoxylin and eosin $\times 115$.

then lessened and it was opened. The left hemisphere of the cerebellum was immediately noted to be raised, and in the ponto-cerebellar angle a large, grey-red tumour was found. During an attempt to remove it extensive bleeding occurred owing to the extreme vascularity of the tumour. For that reason, only a piece of the tumour was taken for histological examination, and, after haemostasis, the wound was closed.

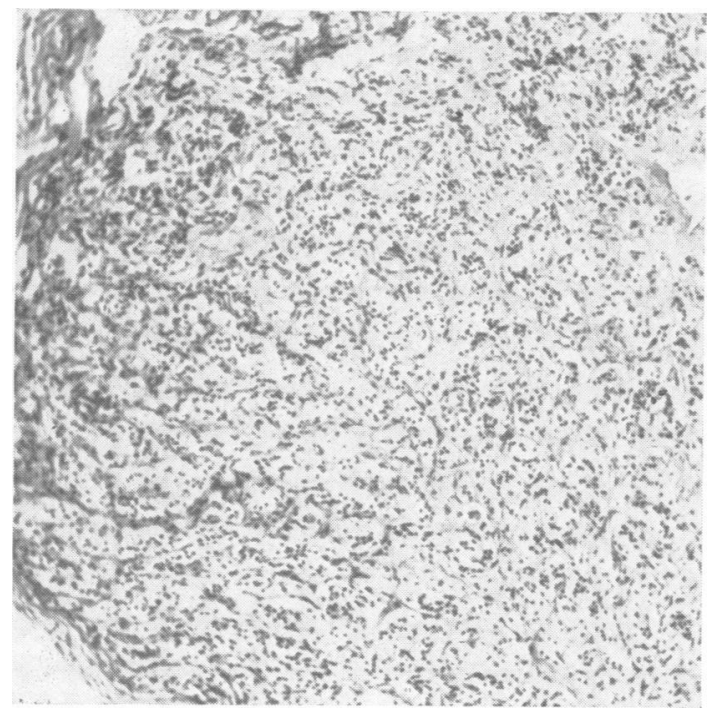

FIG. 3. General view of the tumour with nests and cords of clear cells separated by thin or dilated capillaries. Haematoxylin and eosin $\times 115$.
HISTOLOGICAL EXAMINATION Microscopical examination of two tiny bits of soft tissue, each of them of approximately pinhead size, showed a tumour made of rows and nests of cells with a well-vascularized stroma. The numerous vessels, mostly capillaries with delicate endothelial lining, were found between the rows and nests. In some areas the tissue had a cavernous appearance because of wide vascular sinuses. In the neighbourhood of these sinuses the stroma was fibrosed. The cells had small solid nuclei, mostly in a central position and a clear cytoplasm. The cell boundaries were indistinct (Figs. 2, 3, and 4). The histological diagnosis was chemodectoma (non-chromaffin paraganglioma).

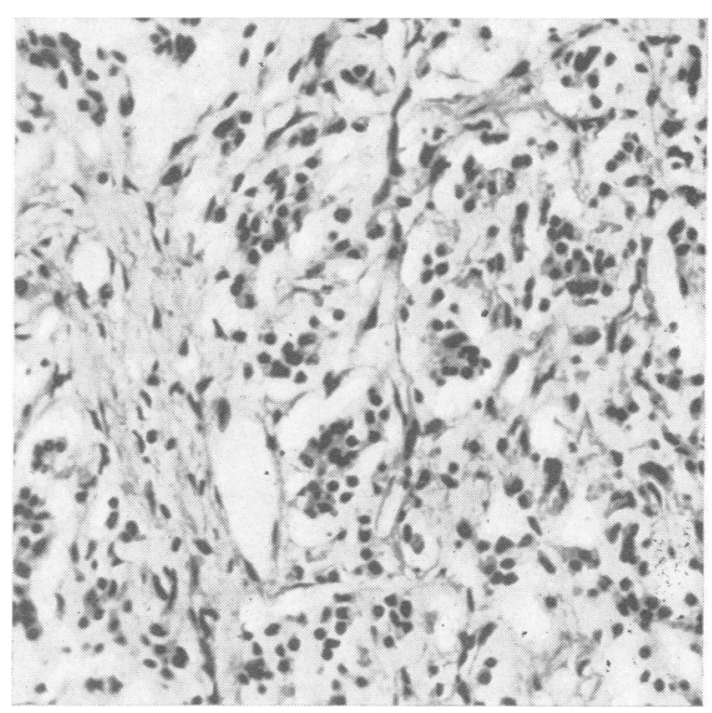

FIG. 4. Structure of the tumour: nests of clear cells with compact nuclei and clear cytoplasm are separated by numerous capillaries. Haematoxylin and eosin $\times 230$.

POST-OPERATIVE COURSE After the operation there was no improvement in the patient's condition and a neurological examination performed on 3 June 1960, one month after the craniectomy, showed no change from the preoperative state. It was therefore decided to administer $x$-ray therapy. The patient was given $2,000 \mathrm{r}$. through two occipital portals between 5 and 29 June 1960. $X$-ray therapy proved to be very effective. One month after beginning therapy, there was subjective improvement and after two months there was no further dysphagia. The patient no longer complained of bruit in the left ear and experienced no pain during movements of the head. The disturbance of balance disappeared and she was able to walk normally.

Neurological examination showed left-sided hypoaesthesia in the distribution of the lower two branches of the trigeminal nerve; corneal reflexes were normal; there was slight atrophy of the left half of the tongue with 
hypoaesthesia and deviation of the lingula to the left; decreased gag and palatal reflexes on the left; atrophy and weakness of the left sternomastoid and trapezius muscles; hypotonia of the left extremities with hyporeflexia but no objective muscle weakness. The Romberg sign showed slight deviation to the left but balance was retained. The patient was discharged from hospital in good general condition on 3 August 1960. She remained, however, under further observation. Despite the satisfactory state of her health, it was decided to repeat the $x$-ray therapy, and she was, therefore, re-admitted to hospital in September and was given a further $1,400 \mathrm{r}$.

At present, two years after treatment, she remains well and has returned to her normal everyday activities.

\section{DISCUSSION}

Tumours of the glomus jugulare usually occur in patients in the middle age groups. According to Bickerstaff and Howell (1953), there have been no cases reported in persons under the age of 17 and in those over 50 the tumour is also rare. Nevertheless, one of the patients in their review was aged 81 years. These findings concur with those of Guild (1953), who, as a result of 88 ear sections, found 248 glomus formations, the largest number being in patients aged 30-39, and the smallest in persons under 20 and over 60 years of age.

Of the 248 glomus formations, 135 were closely associated with the tympanic branch of the glossopharyngeal nerve, and 113 of them with the auricular branch of the vagus nerve. In only $5 \%$ of his cases was Guild unable to find any glomus formation. Fifty-one of the glomera in the region of the jugular fossa were related to the tympanic branch of the glosso-pharyngeal nerve, while 81 of the glomera in this region were related to the auricular branch of the vagus nerve.

Histologically, the jugular body closely resembles the carotid body. Each glomus consists essentially of numerous small blood vessels, capillary or precapillary in size, with epithelioid cells between the vessels.

Whereas the chromaffin reaction is strongly positive in the adrenal medulla, it is doubtfully positive, or more usually negative, in preparations of the carotid and jugular bodies. Therefore, carotid tumours as well as glomus jugulare tumours are designated as being non-chromaffin in nature.

CLINICAL FEATURES In the review of Bickerstaff and Howell (1953) it is noted that $78 \%$ of the cases are in women. They offer, however, no explanation of this phenomenon. Most of the patients gave a long history of illness. Sixty patients consulted a physician only 10 years after the symptoms appeared and 17 of them after 20 years. Even the remaining patients first sought medical advice only after several years had elapsed. Nevertheless, the illness may develop: rapidly, as in the case described by Albernaz ance Bucy (1953) when no more than two months elapse from the primary symptoms to a state of coma.

The clinical features depend on the primary site of the tumour. Capps (1953) classified tumours of the glomus jugulare in two groups: 1 Originating in the middle ear, characterized by deafness and tinnitus? and penetrating through the drumhead into the external auditory meatus; 2 tumours arising in the? neighbourhood of the jugular bulb and invading the middle ear through its floor. These often tend to invade the labyrinth and to spread on the under $\frac{\text { T }}{\bar{T}}$ surface of the petrous bone, giving cranial nerve palsies. According to Capps, these tumours are ofteres so extensive and inaccessible that surgical approachis a matter of great difficulty.

In our opinion, there is good reason to distinguish a third group consisting of tumours localized in the jugular foramen or in the ponto-cerebellar angle and causing a characteristic syndrome. Whereas the tumours arising in the middle ear are par excellenceos 'otological', those belonging to the proposed third group are 'neurosurgical' at the very beginning. की should, however, be repeated that tumours of the glomus jugulare with primary neurological featues are of the utmost rarity.

A tumour of the glomus jugulare arising in posterior fossa (jugular foramen or ponto-cerebelam angle) is characterized by palsies of the seventh $\frac{\tau}{2}$ twelfth cranial nerves and paralysis of the firito and sixth nerves is relatively uncommon. These. tumours also give rise to a 'cerebellar syndrome' (ataxia, positive Rombergism, and adiadochokinesis) Papilloedema in this tumour appears to be more uncommon than in other tumours in the same region.

One of the typical features of a tumour of theo glomus jugulare is the feeling of bruit in the ear probably caused by the high vascularity of the tumour. Poppen and Riemenschneider (1951) suggest, therefore, that a vertebral arteriogram may be help ful in the diagnosis.

A radiograph of the skull in cases of glomus jugulare tumour usually shows clouding of the. mastoid air cells and erosion or destruction of the petrous or occipital bones or enlargement or destruction of the jugular foramen.

TREATMENT Radical removal of the tumour is, of course, the best method of treatment. However because of the marked vascularity of the tumour, operation may cause excessive and dangerous bleeding which may prove very difficult or even impossible to control. We, therefore, feel that in thes presence of excessive bleeding radical surgery is not $\omega$ 
advisable and no more than a decompressive craniectomy should be performed.

$X$-ray and surgical therapy Opinions as to the effects of $x$-ray therapy upon glomus jugulare tumour are divided. The majority of authors are, however, pessimistic as to the results of such treatment. Mattick and Burke (1952) stated that there seems to be no reason for radiation of glomus tumours as, presumably, like carotid body tumours, they are radioresistant. Barton and Thec (1953) stated that radiation therapy had produced no demonstrable effect. Albernaz and Bucy (1953) considered that the tumours did not seem to respond to $x$-ray therapy. Riemenschneider, Hoople, Brewer, Jones, and Ecker (1953) stated that although there was little evidence that radiation therapy accomplished much, the few reports of fair results warranted its use in cases of obvious inoperability.

Bradley and Maxwell (1954) favoured surgical treatment of glomus jugulare tumours although two of their patients were treated with radiotherapy alone. Capps (1953) mentioned that in extensive cases radiotherapy might be the treatment of choice. He also found it effective in cases of local recurrence of the localized type of tumour when the previous treatment had been a radical mastoidectomy. Brown (1953) stated that the therapy of glomus jugulare tumours should include surgical removal or $x$-ray therapy, or both. Williams, Childs, Parkhill, and Pugh (1955) reported that in 13 cases treated surgically there was no immediate improvement. In their opinion the improvement that ensued was due to $x$-ray or radium therapy. Nevertheless, they stated that when cranial nerves are involved radiation therapy seem to have little or no effect in restoring functions. Thoms et al. (1960) are in favour of surgical treatment alone, stating that these tumours are highly differentiated and ordinarily the dosage of radiation required to be lethal to the tumour would simultaneously be expected to be lethal to adjacent brain-stem tissues.

Of the reports in the medical literature concerning the effects of $x$-ray therapy on carotid-body-like tumours, only those of Bevan and McCarthy (1929) and Lahey and Warren (1951) expressed any optimism. It seems that so far the best results in the radiation therapy of glomus jugulare tumour involving pontocerebellar nerves have been obtained by
Alexander and Adams (1953). After biopsy of neoplastic tissue from the ear their patient was given $2,080 \mathrm{r}$. and six weeks later 900 and $1,200 \mathrm{r}$. were administered through left and right occipital portals. In our case, however, after radiation therapy the headache and the disturbances of swallowing and phonation disappeared. Ataxia and paralysis of the palate, as well as the seventh nerve palsy regressed, and the patient's voice became normal, although there was no improvement of the sterno-mastoid paresis and tongue deviation and atrophy. We feel, therefore, that there is no doubt of the effectiveness of radiotherapy in causing regression of the tumour.

\section{SUMMARY}

A case of tumour of the glomus jugulare (nonchromaffin paraganglioma, chemodectoma) of the ponto-cerebellar angle has been reported, showing multiple neurological features with both cranial nerve palsies and signs of cerebellar involvement.

Treatment by radiation after biopsy produced considerable improvement. The value of radiotherapy is discussed.

\section{REFERENCES}

Albernaz, J. G., and Bucy, P. C. (1953). J. Neurosurg., 10, 663.

Alexander, E., Beamer, P. R., and Williams, J. O. (1951). Ibid., 8, 515. , and Adams, S. (1953). Ibid., 10, 672.

Barton, R. T., and Thec, E. J. (1953). J. Amer. med. Ass., 153, 619. Bevan, A. D., and McCarthy, E. R. (1929). Surg. Gynec. Obstet., 49, 764.

Bickerstaff, E. R. and Howell, J. S. (1953). Brain, 76, 576.

Bradley, W. H., and Maxwell, J. H. (1954). Laryngoscope (St. Louis), $64,533$.

Brown, L. A. (1953). Jbid., 63, 281.

Capps, F. C. W. (1953). Excerpta med. (Amst.), Sect. 11. [Oto-RhinoLaryngology] $6,181$.

Guild, S. R. (1953). Ann. Otol. (St. Louis), 62, 1045.

Lahey, F. H., and Warren, K. W., (1951). Cited by Alexander, E., and Adams, S. (1953). In Surgical Practice ol the Lahey Clinic, pp. 149-163. Saunders, Philadelphia.

Mattick, W. L., and Burke, E. M. (1952). Laryngoscope (St. Louis), 62, 311.

Meacham, W. F., and Capps, J. M. (1960). J. Neurosurg., 17, 157.

Poppen, J. L., and Riemenschneider, P. A. (1951). A.M.A. Arch. Otolaryng., 53, 453.

Riemenschneider, P. A., Hoople, G. D., Brewer, D., Jones, D., and Ecker, A. (1953). Amer. J. Roentgenol., 69, 59.

Semmes, R. E. (1951). Discussion of Alexander et al., J. Neurosurg., 8, 522.

Thoms, O. J., Shaw, D. T., and Trowbridge, W. V. (1960). Ibid., 17, 500.

Williams, H. L., Childs, D. S. Jr., Parkhill, E. M., and Pugh, D. G. (1955). Ann. Otol. (St. Louis), 64, 546. 